\title{
Taking social media to a university classroom: teaching and learning using Twitter and blogs
}

\author{
Winner Dominic Chawinga
}

\author{
Correspondence: \\ winnchawinga@gmail.com \\ Department of Library and \\ Information Science, Mzuzu \\ University, Private Bag 201, Luwinga, \\ Mzuzu, Malawi
}

\begin{abstract}
Social media has taken many sectors including the higher education by storm. However, with wide spread fears that social media may be a distractor to pedagogy, this paper investigated how social media facilitates teaching and learning. Unlike most prior studies which relied much on soliciting mere views from students and lecturers about their intentions to use or not to use social media, this study incorporated Twitter and blogs into two undergraduate courses offered in the Department of Library and Information Science at Mzuzu University which is a public university in Malawi. Data were collected in two ways: first, analysis of blog and Twitter posts by students and second, a questionnaire was sent to 64 students to find out their perception towards the use of blogs and Twitter in a classroom environment. Results suggest that if appropriately deployed, Twitter and blogs are catalysts for the much hyped learner-centred approach to teaching because using these technologies, it emerged that students shared and discussed course materials, posted their course reflections and interacted amongst themselves and with their lecturer 24/7. Challenges faced include cost of internet data bundles, inaccessible Wi-Fi, poor bandwidths and insufficient computers.
\end{abstract}

Keywords: Blogs, Learning, Students, Social media, Teaching, Twitter

\section{Introduction}

Lecturing is a term that seems to be either taken for granted or misused by most instructors. Normally, lecturers go to class loaded with course content to deliver to students while being mindful of the limited time they are assigned per week, month or semester. According to Jones (2015:91), "Many of us [lecturers] leave such a class confident that teaching has taken place, if not always learning". More often, lecturers monopolise all the time during the lecture thereby denying inertly listening students an opportunity to participate in the classroom and more so, allow little feedback from students at the expense of coverage of course content. Jones (2015:93) wonders on how lecturers might shift from 'uploading' content to students to a better teaching technique that allows students to participate more enthusiastically in the teaching and learning process i.e. learner-centred approach. Some researchers (Menkhoff, Chay, Bengtsson, Woodard, \& Gan, 2014; Wheeler, 2010:110) are of the view that forms of social media technologies such as Twitter and blogs can jointly be an impetus to

(c) The Author(s). 2016 Open Access This article is distributed under the terms of the Creative Commons Attribution 4.0 International License (http://creativecommons.org/licenses/by/4.0/), which permits unrestricted use, distribution, and reproduction in any medium, provided you give appropriate credit to the original author(s) and the source, provide a link to the Creative Commons license, and indicate if changes were made. 
enable both students and instructors actively and instantly participate and communicate with each other on educational activities.

Worth noting is that during a review of literature, the author noticed one intersected discourse in relation to the topic under review: whether Web 2.0 is social media or vice versa. For example, what is ostensibly clear is that social media existed before Web 2.0-first coined by O'Reilly in 2005. For example, MySpace was developed in 2003 according to Kaplan and Haenlein (2010:60) but literature characterises it as almost the same as Web 2.0. So what is Web 2.0 and social media? Kaplan and Haenlein (2010:61) and Barczyk and Duncan (2011:267) refer to Web 2.0 as technological foundations or platforms on which applications that support user generated content are hosted. These applications that support user generated content based on the versatility of Web 2.0 features are called social media and some of them include "Facebook, Google+, Orkut, MySpace, LinkedIn and Twitter" (Barczyk \& Duncan, 2011:267). Before the invention of Web 2.0, a period best described as Web 1.0 era, the concept of the web was principally based on 'content publishing' by content creators through personal or institutional web pages like Encyclopedia Britannica Online (see Kaplan \& Haenlein, 2010:61). However, in a Web 2.0 era, it is possible for end-users to make use of mobile and webbased technologies to share, co-create, discuss and modify user-generated content via these highly innovative platforms. Thus, for the purpose of this study, the author adopts a description of Web 2.0 and social media as defined by Kaplan and Haenlein (2010:61) who consider "Web 2.0 as a platform for the evolution of Social Media" and further define social media as "a group of Internet-based applications that build on the ideological and technological foundations of Web 2.0, and that allow the creation and exchange of User Generated Content".

There is still confusion in the literature (see Bull et al., 2008: 106; Azab, Abdelsalam, \& Gamal, 2013) when providing examples of social media. For example, some researchers classify Twitter, blogs and Facebook as Web 2.0 technologies whereas other researchers classify them as social media. The fact that Web 2.0 and social media complement each other in affording end-users in cyberspace an opportunity to create, modify and publish content in a participatory and collaborative way explains why the two terms are oftentimes used interchangeably by most researchers. Kaplan and Haenlein (2010: 61) make the correct assumption that that there is no systematic way in which different social media applications can be categorised. Kwanya, Stilwell, and Underwood (2012) makes a point that Web 2.0 is a platform service for social media.

The author has taught at a public university for 5 years and noted that the traditional medium of face-to-face teaching comes along with many benefits. However its dependency on time and space among others, becomes a major setback. In that respect, Dzvapatsva, Mitrovic, and Dietrich (2014) argue that a compendium of social media technologies which have "recently exponentially grown and become prevalent" have a capability to supplement traditional teaching and learning approaches in institutions of higher learning. Studies have shown that tweeting is regarded as a more interactive and exciting way of learning compared to traditional knowledge transfer tools such as lectures (Menkhoff et al., 2014). Some of the most common social media technologies according to Chawinga and Zinn (2016), Dzvapatsva et al. (2014) and Gikas and Grant (2013), include social networking sites (SNS) such as Facebook, Twitter, MySpace and LinkedIn; media sharing sites, such as YouTube, Flickr and Tumblr; wikis and blogs 
and syndication of content through Rich Site Summary (RSS) feeds. Since social media applications have rapidly developed, evolved, expanded, and grown in numbers and forms, it may not be possible to efficiently research how they can collectively be applied in a classroom environment especially if the study focusses on their practical use other than merely soliciting views from either students or instructors. It is against this backdrop that the current study selects only two forms of social media (Twitter and blogs) in regards to their use in a university classroom environment.

\section{Motivation and research questions}

Three factors motivated the author to conduct this study. First, it is particularly informed by a teaching technique adopted from the author's former lecturer and supervisor Dr Sandy Zinn at the University of the Western Cape in South Africa who used social media in a Masters class of 2013, including Twitter, blogs and wikis. Looking at the benefits of this approach, the author decided to test the use of Twitter with his Library and Information science students at a public university in Malawi. Secondly, the study builds on the findings of the author's master's thesis which showed that lecturers and students at Mzuzu University (MZUNI) had to some extent, adopted some Web 2.0 technologies in their teaching and learning activities respectively. Since the findings of the thesis were arrived at by merely soliciting views from respondents though a questionnaire, in the current study, the author incorporated Twitter and blogs into two existing semester courses offered in the Department of Library and Information Science (LIS). Thirdly, while Internet, laptops, smartphones and other mobile technologies are increasingly becoming a common sight in university environments amongst students, Chawinga and Zinn (2016) and Menkhoff et al. (2014) independently observe that application and use of social media platforms such as Twitter and blogs amongst students and lecturers with a focus on a particular course in classroom is still rare. More so, there are claims about an increase in visibility of social media in higher education settings which instructors are increasingly adopting to mediate and enhance their instruction as well as promote active learning for students (Tess, 2013). However, Tess (2013) argues that empirical evidence does not adequately support these claims. To this end, the study answers two key research questions as follows:

- What are the benefits reaped from the practical use of social media in a university classroom?

- What are the factors that affect the use or non-use of social media by students in a university classroom?

\section{Literature review}

Literature is replete with previous studies undertaken to demystify the use of social media in classroom environments of higher education. In the subsequent sections, the author reviews and synthesises some of the most potent studies that relate quite well with the current study.

Proponents of Web technologies in education have long argued that these technologies supplement and upgrade the widely accepted traditional delivery of lessons to students. For example, with reference to traditional learning, Vygotsky (1980) argued that human beings learn best if there are some sorts of interaction through collaborative 
learning and group work so that students work together on a task. In this social media era, the said interaction and collaboration in teaching and learning is now implemented virtually without worrying about time and space limitations or barriers. To this end, some educational researchers have coined the term Learning 2.0 in reference to "a spectrum of all pedagogical approaches that draw heavily upon Web 2.0 tools [Facebook, Twitter, blogs, WhatsApps, etc.] and services" (Wheeler, 2010:107).

\section{Benefits of social media in pedagogy}

According to Jones (2015:93), social media technologies such as blogs and Twitter are no longer only used for leisure. Rather, over the years, these technologies have also become platforms for interacting and engaging with learners. In their recent study about the tweeting behaviour of undergraduate students in some universities in Singapore, Menkhoff et al. (2014) find that among other benefits, Twitter enables students to have "a voice, to be more engaged and to interact more freely with both their peers and the instructor via knowledge sharing and twitter discussions". This means that students who are expectantly captive in traditional approach to teaching, are increasingly offered an opportunity to provide prompt feedback to instructors, an element that Schroeder and Greenbowe (2009) and Jones (2015:93) say leads to the much treasured student-centred learning approach. Getting feedback from students is glorified by Menkhoff et al. (2014) as an important aspect through which an instructor can monitor if students have comprehended the course content taught in class thereby allowing the instructor to identify knowledge gaps and address them on the spot.

More importantly, unlike the traditional face-to-face medium of teaching which have some space and time restrictions, "... [in] electronic media, the world becomes the classroom, available 24/7, and not confined to Mondays to Fridays" (Dzvapatsva, Mitrovic, \& Dietrich, 2014). The notion of $24 / 7$ in this context simply suggests that embracing social media enables students and lecturers to interact outside the formal learning time with more flexibility. It does not imply that learning is officially enforced to take place during the weekend or at night.

Whether computer-based or mobile-based, Menkhoff et al. (2014) and Wheeler (2010:103) identify three usefulness of social media in a university classroom. First, social media supplements blended learning which helps students create positive contextual learning in relation to pedagogical objectives. Twitter for example, can be used to engage with students as learning happens during face-to-face classes and; it can also be used to communicate with students when they are at their homes (the period of distance learning). Second, social media affords students to engage in collaborative learning and finally, social media motivates students to post comments or questions to blogs or Twitter about their subject matter. In addition, social media provides several pedagogical affordances in higher education including open publishing, new communication styles and texts, expressing personal identity and experience, co-creation and collaboration, and content management (De Wever, Hämäläinen, Voet, \& Gielen, 2015; Terrell, Richardson, \& Hamilton, 2011: 848; Waycott et al., 2010; Wheeler, 2010).

Some previous studies have provided evidence about the benefits and use of Twitter in classroom environments. Jones (2015) used Twitter to teach a literature class for 30 undergraduate students at the University of California that put emphasis on students' 
participation. It is reported in the study that "my students soon embraced Twitter as a collaboration tool, and increasingly came to class with improved attitudes toward, and readiness for class discussions" (Jones, 2015:91). In a related study, for a full semester, Soares (2008) used blogs to teach English as a foreign language at a Brazilian university. At the end of the semester, he distributed an online questionnaire to investigate students' perception about blogs as learning tools and results showed that blogs profoundly helped students improve their writing skills in English language by accessing tutorials in the form of Podcasts and videos shared on their blogs.

Evidence about the benefits of social media in higher education are also highlighted in a report by Conole and Alevizou (2010) commissioned by the Higher Education Academy in the United Kingdom. By drawing data from published reports, conference papers, journal articles and anecdotal evidence, Conole and Alevizou (2010) make a statement that Twitter and blogs and other Web 2.0 technologies are catalysts of scholarly practice and the sharing of designs and good practice. This is made possible by allowing students to participate in a distributed network of educators and researchers and to co-create knowledge and develop a skill of critique of content (Conole \& Alevizou, 2010).

A depiction of social media in pedagogy is provided by Wheeler (2010) who focusses on two distinct but interrelated approaches to pedagogy facilitated by social media namely; reflective and collaborative activities of learning. Reflective activities in this context entail students' ability to think critically about what they have learnt thereby being able to "apply previous learning to new situations" (Wheeler, 2010:106). Given that knowledge gets outdated very quickly, it becomes paramount for students to reflect on what they have learnt in class and keep abreast of fastpaced changes and keep themselves relevant in their future competitive job market. Blogs are described by Wheeler (2010:106) as web tools that promote reflective learning while as wikis are meant for collaborative learning. Figure 1 below provides details of a diagrammatical depiction of social media in pedagogy by Wheeler (2010:111).

\section{Challenges that affect incorporation of social media in pedagogy}

Recent studies suggest that there are various challenges militating against successful integration of most social media in teaching and learning in university environments. For

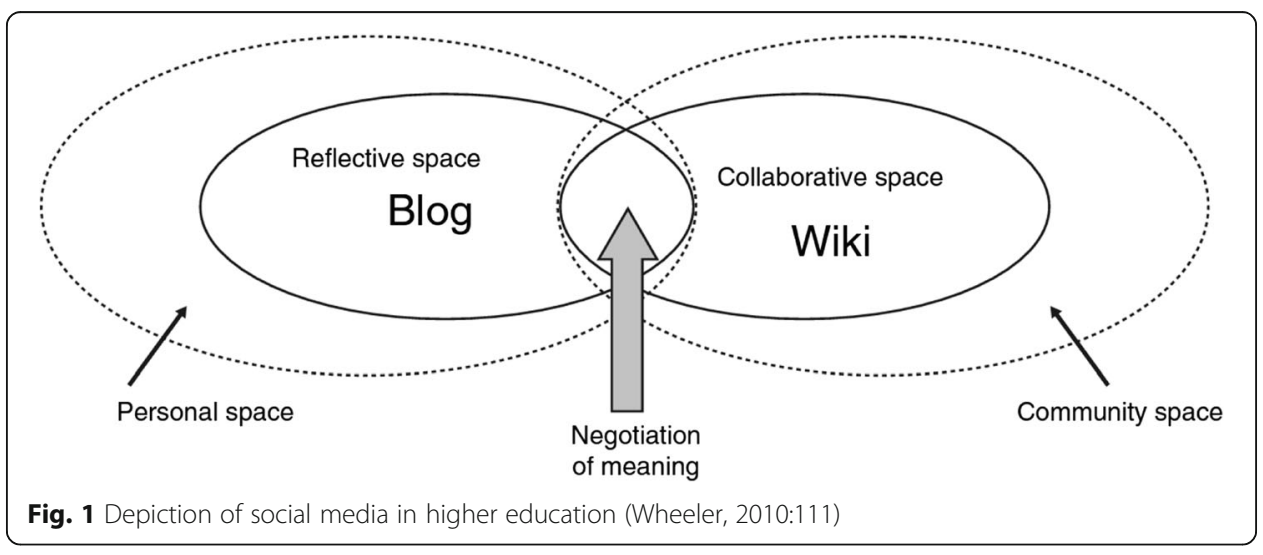


example, in Africa, more specifically at the University of the Western Cape in South Africa, Dzvapatsva, et al. (2014) report that some of the factors that militate against the use of social media include lack of technical skills that students experience when learning or using portals of social media, inadequate technological infrastructure and bandwidth which results in students abusing it. The problem of Internet bandwidth seems to be common in most African countries because Chawinga and Zinn (2015) also reports of a similar problem at MZUNI in Malawi.

Additionally, literature shows that opponents of social media use in a classroom continue to downplay the value of such technologies. Among others for example, Barczyk and Duncan (2011:271) observe that critics of social media in academia often point out that social networking sites offer poor reference material often generated by unreliable sources. Some instructors in higher learning institutions have consequently been reluctant to adopt social media in their teaching and learning activities. Some instructors perceive social media such as Twitter and Facebook as distracters to learning (Galagan, 2010). Barczyk and Duncan (2011: 271) and Harris and Rea (2009) highlight additional challenges which include absence of computing resources, disruption of web-based resources and plagiarism due to openness of content whereby students can copy and paste. Perhaps, to outshine these detractors and challenges reported in this section, it is important to focus on how best these technologies can be put into good use to yield positive results. This can be achieved by aligning social media activities with lesson objectives or curricula (Kietzmann, Hermkens, McCarthy, \& Silvestre, 2011; Szapkiw \& Szapkiw, 2011: 363; Wheeler, 2010:104).

From an analysis of a literature systematically searched from databases such as Web of Science, EBSCOhost, and ERIC and Google Scholar, Tess (2013), highlights some factors that contribute to the low uptake of social media in higher education. They include instructors' slowness in adopting technology as an educational tool, decisions related to educational technology and its place in the curriculum and more importantly, Tess (2013) argues that integration of social media is a choice made at the instructor level rather than at an institutional level.

Despite evidence about the benefits accrued from the application of social media in higher education, there are some fundamental paradoxes and puzzles that remain inhibitors to smooth adoption of these technologies. A study by Conole (2010) revealed a number of such issues including privacy where it is reported that there is lack of understanding of the implications of adopting more open approaches in technological environments, lack of rewards or incentives for instructors using these technologies in class, lack of skills to use these technologies and a belief that these technologies may not necessarily work in a classroom.

\section{Methodology}

Methodologically, the study was inspired by various earlier studies (Barczyk \& Duncan, 2011:271; Jones, 2015:101; Menkhoff et al., 2014). The study was conducted in two main phases. First, students were asked to create blogs and Twitter accounts followed by tweeting and blogging. In the second phase, the author analysed tweets by students in addition to distributing a questionnaire to students. The questionnaire collected feedback from students in regards to the use of blogs and Twitter in a classroom. In 
the following section, the author discuses in more details how the study was implemented.

\section{Phase one: creation of Twitter and blog accounts}

Barczyk and Duncan (2011:271), Jones (2015:101), Menkhoff et al. (2014) and Szapkiw and Szapkiw (2011:361) have recommended some guidelines that a lecturer intending to use twitter or blogs in a classroom environment should bear in mind. The author adopted some of the guidelines as discussed in this section.

The author adopted his existing Twitter account just for teaching. Following Menkhoff et al. (2014) and Jones's (2015:102) recommendations, the author asked students to create dedicated Twitter accounts for the purpose of learning and interacting with me and fellow students. In his case, the author used his existing Twitter account which he created during his masters studies in 2013. The author asked each of his students to create a Twitter account.

The author created hash tags. : In this study, two hash tags were used for the two classes: \#DL and \#IR for Digital Librarianship (LIS3604) and Information Storage and Retrieval (LIS2303) respectively. This was important because it allowed students to easily follow class conversations. Parr (2009) and Jones (2015:102) caution instructors to do a thorough research to ensure that the hash tag is not being used by other professionals. By drawing lessons from Parr (2009) and Jones (2015:102), the author did a thorough check on Twitter to ensure that the adopted hash tags are not being used by any other professional or group on Twitter.

The author set clear expectations of how his students were expected to use Twitter and blogs. The author communicated to students that he was going to monitor their tweets, blog posts and comments and a grade could be awarded at the end of the semester which wholly contributed to the continuous assessment. To bring some sanity in the use of Twitter and blogs for class work, it becomes important that students are informed in advance of what they are supposed to do. According to Comm (2009), such an arrangement results into an excellent review of tweet categories and functions and blog functions.

The author rewarded students for their substantive and helpful Twitter and blog participation. The aim was to motivate students to contribute tweets, blog posts and comments that are valuable and relevant to the topic or subject of discussion. Drawing lessons from Jones (2015:102), the author made policies known beforehand about what students were expected of them to invest in the course.

The author tweeted multiple media. This is an import aspect of microblogging in education because it challenges students to direct colleagues and in some cases the instructor to "audio, and video that might help them understand the settings and context of assigned texts" (Jones, 2015:102). The author also encouraged students to share a wide range of multimedia via their blogs and Twitter.

The author divided students into groups. According to Barczyk and Duncan (2011:275), this motivates students to work together in preparation for their mid-term or final examinations through holding cyberspace meetings using web tools such as blogs. In this study, each class was divided into three groups with an average of 10 members through which they collectively created blogs and prepared weekly blog posts summarising what had been covered in classes of each week. Blog posts (not comments) were assessed collectively i.e. per group. 
The author asked students to use their real names instead of using anonymous user names: Menkhoff et al. (2014) argue that students and some instructors may require students to use anonymous user names while others may require students to use their real names in a twitter discussion. Since the author was expected to reward students with a grade as part of their continuous assessment for their participation, all students used their registered reals names. The author had to assess the progress of students' tweets, blog posts and comments and scores were awarded based on the individual student's quality of contribution.

\section{Phase two: distribution of a questionnaire}

Borrowing from Menkhoff et al. (2014), the author self-administered a questionnaire to all 36 and 28 level two and three undergraduate students respectively at the end of the semester, specifically after they had written end of semester examinations. This population was much better as compared to other studies such as that of Jacquemin, Smelser, and Bernot (2014) who in a similar study targeted only 22 undergraduate students although in their study, they also targeted faculty staff. Apart from background information, the questionnaire had two additional sections (each with a mix of closed-ended and open-ended questions) which included benefits of Twitter and blogs in teaching and learning and challenges affecting the use of Twitter and blogs in teaching and learning. All students responded to the questionnaire and of these, 28 (43\%) were males and $36(56 \%)$ were females.

Thematic analysis was applied on analysing qualitative data. Braun and Clarke (2006) defines thematic analysis as a method for identifying, analysing, and reporting patterns (themes) within data. When dealing with web based content particularly blogs, it is necessary to identify variables related to the information that bloggers provide (Kim \& Kuljis, 2010:372). Such information may be selected according to what researchers are interested in. In this study, the focus was on students' posts and comments in relation to educational endeavours and, commonly recurring and prevalent themes were identified to help answer the research questions.

Statistical Package for the Social Sciences (SPSS) was used to analyse quantitative data that was collected using a questionnaire. Using SPSS, frequencies and percentages were depicted in tables. Data collected using a questionnaire were triangulated with data collected through an analysis of posts to Twitter and blogs by students.

\section{Results and discussion}

In all, there were 9000 students' tweets over a period of 12 weeks with the least twitter having tweeted 20 times and the highest twitter with 320 tweets. In his effort to communicate with students, the author tweeted 350 times within that period of time. Blog transactions which included group blog posts, blog comments and other media content (audio and video) totalled well over 500. This section presents and discusses the results realised from the study. The findings are presented in line with the following broad themes underpinning the study:

- Benefits reaped from the practical use of social media in a university classroom

- Factors that affect the use or non-use of social media by students in a university classroom 


\section{Benefits of social media}

What technological devices did students use to access Twitter and blogs?

Findings presented in Table 1 which allowed multiple responses show that 55 (85\%) students used personal phones for their Twitter and blog activities. Nearly all the students who used mobile phones to access Twitter and blogs indicated they used these technological devices because they are relatively cheaper and easier to access as compared to the computers available in the University Library. The other motivational reason for the use of mobile devices was that students were able to use these devices anytime without having to worry about the closure of the library and other access points. Of the students who used desktop computers in the University Library, nearly third indicated they used it during working hours. According to the findings, students accessed Twitter and blogs in the Library Internet room because Library offers subsidised Internet services as compared to buying Internet data from mobile services providers. Some students mentioned of desktop computers that they accessed in the three computer laboratories available on the University campus where students pay for Internet services at subsidised fees.

To which extent did the use of Twitter and blogs benefit students in their course of study? Students were asked the purposes they used Twitter and blogs for. Findings presented in Table 2 show that the use of the two social media technologies by students was mainly for the accomplishment of academic activities. This is the case because in these particular courses, the two forms of social media were mainly adopted to facilitate teaching and learning. Given that the two social media have unique characteristics and capabilities, though with similar purposes, the purposes and benefits for each of the two were explored separately.

\section{Benefits of Twitter}

A thematic analysis of tweets revealed two main purposes: instant communication and content sharing. The themes are well corroborated with participants' views solicited through a questionnaire as presented in Table 2 in which it is observable that most of them agreed or strongly agreed that they benefitted from Twitter through interactive learning, instant communication and independent learning. The results are realistic because the author made all communications to students including lecture notes, feedback and class cancellations through Twitter. For example, when the author posted this tweet: \#DL \& \#IR: download lecture notes here https://t.co/qKGBX9o091 \& https:// t.co/Mpg6WIxOAs respectively", it was retweeted 60 times and favoured 63 times within half an hour. The lecture notes were uploaded on Google Drive (another form of social media which is not part of this study's scope) and the author shared the link

Table 1 Devices used by students to access Twitter and blogs $(n=64)$

\begin{tabular}{lll}
\hline Technological devices & $n$ & $\%$ \\
\hline Personal smart phone/mobile phone & 55 & 86 \\
Desktop computer in the library & 35 & 55 \\
Personal laptop & 18 & 28 \\
Personal IPad/Tablet & 6 & 9 \\
IPad/tablet in the library & 1 & 12 \\
Desktop computers & 18 & 28 \\
\hline
\end{tabular}


with students by tweeting. Google URL Shortener (https://goo.gl/) was used to shorten uniform resource locators (URLS) of links which were alarmingly long. Some researchers (Farkas, 2012:85; Franklin \& Harmelen, 2007) have noted that these technologies offer an opportunity to shy students to freely express themselves. In the current study, only a small number of students indicated were shy because these students have stayed together and are used to each other. However, a departure from face-to-face interaction with students also profoundly helped to increase students' participation in class discussions. For example, when the researcher asked open-ended questions in class, there could sometimes be total silence. However, by asking the same question via Twitter, the response rate was remarkable. This is probably the reason Conole and Alevizou (2010) argue that Web 2.0 approaches require pedagogical rethinking by challenging existing approaches to curriculum design, delivery and assessment.

As a lecturer, using Twitter and blogs enabled me extend the time for interacting with students as it was not possible to teach, respond to students' queries and to give students a chance to comment in a face-to-face meeting in a classroom. With Twitter, students were able to ask me any question anytime as long as they were connected to the Internet. Using blogs, students could post their assignments anytime without being worried that they could find the lecturer's office closed or, there was nothing like racing against the official working hours. Arguably, this is one of the benefits of social media so much so that one student commented that "I was able to communicate with the lecturer while covered in my blankets and I was glad that the lecturer was able to promptly respond to my queries even at mid-night". Another student who also agreed said "Each time I was reading and I came across a difficult concept, I could just tweet and the response could be immediate and overwhelming". The fact being drawn from the findings is that incorporating social media in teaching works to the advantage of lecturers and students as it plays supplementary role to traditional face-to face approach to teaching. This is probably the reason Barczyk and Duncan (2011:270) postulate that "If tools [social media] are available to help better engage and educate students, they should be incorporated into the curriculum, not exclusively, but rather, in a supplemental fashion."

\section{Benefits of blogs}

Within 12 weeks, the six groups with an average of 10 students had created in excess of 500 transactions including blog posts, content sharing (text and video) and comments. By analysing blog transactions, the author noticed that the principal benefits included reflection on what students had covered in class or read in relation to the content covered in a particular week. Sixty percent of blog transactions comprised weekly summaries which were collectively assessed and 40\% comprised individual comments which were individually assessed for commenting on own or blogs of other groups. As was the case with Twitter, students found blogs useful by allowing them to learn without always relying on the lecturer. See Table 2. While independent learning was achieved on Twitter through instantly asking questions and clarification, on blogs, this was achieved though students' reading of essays and reflections of blog posts. A thematic analysis of blog posts by students reveals the followings titles (these are just a selection from many posts) of reflective essays: 
Table 2 Benefits of Twitter and blogs $(n=64)$

\begin{tabular}{|c|c|c|c|c|}
\hline \multirow[t]{2}{*}{ Benefits } & \multicolumn{4}{|c|}{$\%$ Frequency of participants } \\
\hline & $\begin{array}{l}\text { Strongly } \\
\text { agree }\end{array}$ & Agree & Disagree & $\begin{array}{l}\text { Strongly } \\
\text { disagree }\end{array}$ \\
\hline \multicolumn{5}{|l|}{ Twitter } \\
\hline $\begin{array}{l}\text { It helped learn from friends without relying on the } \\
\text { lecturer }\end{array}$ & 52 & 44 & 44. & 0 \\
\hline $\begin{array}{l}\text { It helped me participate in course discussion with } \\
\text { colleagues }\end{array}$ & 47 & 45 & 45 & 5 \\
\hline Blog helped me reflect about what we covered in class & 4 & 47 & 3 & 3 \\
\hline It helped me prepare for my future work places & 41 & 30. & 30 & 6.3 \\
\hline $\begin{array}{l}\text { Blog helped me publish my essays and other course } \\
\text { work }\end{array}$ & 34 & 23 & 23 & 11 \\
\hline $\begin{array}{l}\text { It helped me communicate course reflection with } \\
\text { colleagues }\end{array}$ & 34 & 53 & 53 & 3 \\
\hline Blog helped me share course content with colleagues & 30 & 61. & 61 & 3 \\
\hline $\begin{array}{l}\text { It helped me share video, images and audio with } \\
\text { colleagues }\end{array}$ & 20 & 13 & 13 & 30 \\
\hline \multicolumn{5}{|l|}{ Blogs } \\
\hline $\begin{array}{l}\text { Helped me learn from friends without relying on the } \\
\text { lecturer }\end{array}$ & 47 & 47 & 3 & 3 \\
\hline It helped me prepare for my future work places & 44 & 23 & 23 & 9 \\
\hline It helped me communicate instantly with the lecturer & 44 & 48 & 3 & 5 \\
\hline It helped me receive immediate feedback from lecturer & 42 & 47 & 3 & 3 \\
\hline It helped me communicate instantly with colleagues & 38 & 48 & 8 & 6.3 \\
\hline It helped me discuss content with colleagues instantly & 38 & 48 & 9 & 3 \\
\hline $\begin{array}{l}\text { It helped me share content with colleagues and the } \\
\text { lecturer }\end{array}$ & 36 & 59 & 3 & 2 \\
\hline It made the lessons more interactive & 33 & 60 & 5 & 2 \\
\hline It helped me think critically before tweeting content & 33 & 62 & 2 & 2 \\
\hline It helped me receive lecture notes from a lecturer & 31 & 64 & 2 & 3 \\
\hline It helped me post urgent questions and seek answers & 31 & 55 & 11 & 3 \\
\hline Am shy so it was easier to comment online than in class & 19 & 19 & 33 & 28 \\
\hline
\end{tabular}

- Retrieving non-textual information: some reflections;

- Challenges against a smooth implementation and adoption of digital libraries: what can Africa learn from the developed world; and

- A slide show of the main topics covered in class this semester: click here to watch.

A further analysis of students' blogs posts showed that students actively participated in blog discussion as evidenced by a selection of some interesting comments as follows:

- Thank you for this well summarised essay, you have enlightened me on the types of metadata;

- Much as your summary reflects what we covered in class, I suggest you should improve on your grammar because your blogs are accessible on the Google [open web]";

- You have mentioned of digital curation, can someone shed more light on this concept; is it the same as big data?; and 
- Your summary is as good as notes prepared by the lecturer, thanks for posting guys. I have learnt a lot on aspects of multimedia information retrieval.

These findings replicate those reported by Soares (2008) who equally found that the use of blogs helped students to improve their learning by accessing other online applications such as YouTube and Podcasts which were shared on their blogs. Wheeler (2010) also found that the use of social media in a classroom contributes to reflective learning which implies that students develop abilities to think critically about what they have learnt thereby being able to "apply previous learning to new situations" (Wheeler, 2010:106). Similarly, Deng and Yuen (2011) who upon surveying student teachers' experiences with the integration of a weblog during their practicum, found that blogs supported self-expression and self-reflection, as well as social interaction and reflective dialogue.

\section{What do students find to be the benefits of using Twitter over blogs and vice versa?}

The questionnaire allowed students to answer an open ended question and express their views as to why they found using Twitter advantageous over blogs and vice versa in their educational activities. A thematic analysis of the students' responses is presented in Table 3 below. It is clear from the findings that Twitter was hailed mainly for its timeliness i.e. students could receive instant messages on their mobile phones as attested by the following comment by one respondent: "Mostly, feedback was instant, as at least some colleagues were always online including the lecturer". The fact that Twitter has a limit of 140 characters, it required students to think critically so as to communicate their point within such a limited number of words or characters. This enforced creativity in students as attested by one student who commented that "Twitter made me think critically as I knew [that] inappropriate tweeting could distort the meaning of my post which needed 140 or less characters". In this way, students learnt skills in both blogging and tweeting to summarise content such that one respondent reasoned that "I learnt summarizing skills; summarizing what we had covered in class was improved over time and my online communication skills improved greatly with my friends". The findings reinforce conclusions made by Conole and Alevizou (2010) that use of social media tools such as blogs and Twitter cultivate a culture of critiquing content amongst students in higher education.

The major breakthrough in using blogs according to the findings is that it allowed students to be compressive in their posts and comments as there is no word limit. For example, one respondent commented that "blogs were beneficial in such a way that it allowed more content because students were able to summarize what was covered in class unlike Twitter which allowed fewer characters". Worth mentioning is that while it could take time to access blogs, accessing Twitter was instant. This is probably the most defining difference between the two types of social media. In most cases, blogging depends on Twitter as students could only ensure their posts reached their colleagues on time by tweeting their blog posts.

Generally, according to the findings, Twitter and blogs allowed students to learn from their friends through comments and posts although students found it easier using Twitter than blogs. Most of the students mentioned statements similar to the one made by their 
colleague who said that "a blog was not such beneficial because it was not easy to access, it needed orientation" and another student who agreed said "It was difficult for me to log in to blog as such it did not benefit me but Twitter was truly flexible".

One of the most common denominators between the two social media tools however, is that both Twitter and blogs, did not require students to meet physically to work in groups as they formed online groups where they virtually accomplished their class work. The results uphold earlier claims by Ellison (2008), Jacquemin et al. (2014) and Roblyer, McDaniel, Webb, Herman, and Witty (2010) that social media networks in higher education have been glorified as an avenue to improve scholarship and learning. In addition, the findings replicate those previously reported by Ajjan and Hartshorne (2008), Bosch (2009), Browning, Gerlich, and Westermann (2011), Maloney (2007), Mason (2006) and Mazman and Usluel (2010) who equally found that social media technologies facilitate active learning, collaboration, interaction, information and resource sharing, increased communication and enhanced discussion between teachers and students.

The research strategy employed in this study helped to realise evidence based results because of its approach unlike prior studies by Conole and Alevizou (2010) and Tess (2013) who collected data through reviewing and analysing published reports, conference papers, journal articles and anecdotal evidence. A rather somehow similar strategy was used by Jones (2015:91) who used Twitter only in teaching a literature class. Thus, unlike previous studies that focused on a particular social media such as Twitter or by reviewing existing literature, a combined use of two social media tools (Twitter and blogs) in this study allowed students to have an opportunity to express their content in more details via blogs and to develop skills in summarising content with a few characters via Twitter.

Table 3 Benefits of Twitter and blogs compared

\begin{tabular}{|c|c|}
\hline Advantages of Twitter over blogs & $\%$ \\
\hline $\begin{array}{l}\text { Twitter allowed students to get instant response through alerts of their phone ringtones than a blog } \\
\text { that required them to log in }\end{array}$ & 51.6 \\
\hline Communicating using Twitter was instant because of the availability of Twitter application on students' phones & 46.9 \\
\hline Twitter is more beneficial since it helped students interact with friends and read and listen to news than blog & 42.2 \\
\hline $\begin{array}{l}\text { Twitter made students think critically as they knew inappropriate tweeting could distort the meaning } \\
\text { of their tweet which needed } 140 \text { or less characters }\end{array}$ & 40.6 \\
\hline $\begin{array}{l}\text { Twitter had more participants than the blog and it had immediate responses from other fellow } \\
\text { classmates }\end{array}$ & 34.4 \\
\hline Interactive learning that did not require students and their friends to be physically present & 34.4 \\
\hline Twitter was easier than blogs because it could be done even on basic phone & 29.7 \\
\hline Feedback was instant, as at least some fellow students were always online, including the lecturer. & 20.3 \\
\hline Advantages of blogs over Twitter & $\%$ \\
\hline $\begin{array}{l}\text { On blogs students got a summary of what they had learnt in class which helped them to understand } \\
\text { the concepts better }\end{array}$ & 46.9 \\
\hline Helped students to reflect about what they had covered in class & 43.8 \\
\hline $\begin{array}{l}\text { Blogs enabled students to publish more content as compared to twitter which is limited by number of } \\
140 \text { characters }\end{array}$ & 43.8 \\
\hline $\begin{array}{l}\text { It helped students publish their essays and share other forms of media content course works such as } \\
\text { video and audio }\end{array}$ & 42.2 \\
\hline $\begin{array}{l}\text { On blog, students got information of various groups while in Twitter they only got information from } \\
\text { friends they followed }\end{array}$ & 37.5 \\
\hline Helped students to learn summarizing skills by summarizing what they had covered in class. & 37.5 \\
\hline
\end{tabular}




\section{Factors for use or non-use of social media}

This section deals with the factors that influenced students to use or not-to-use social media in their academic work.

\section{What encouraged students to actively participate in Twitter and blog class activities?}

The key factors that encouraged students to use social media were realised through an open-ended question. A thematic analysis of the findings is depicted in Table 4. All 64 $(100 \%)$ students attributed their use of social media because they wanted to attain good grades for their continuous assessments. A comment that follows suggests that some students could not have used these technologies if no reward was attached: "Marks that were to be awarded. I don't really use social networks and I am not there very active". The findings give substance to earlier claims by Jones (2015:102) who says as a caveat for maximised use of social media by students in a classroom environment, instructors should set a clear framework well in advance on how students are going to be rewarded for their participation.

Apart from awarding marks to students for creating Twitter accounts and blogs with their subsequent posts (this was made very clear beforehand), retweeting any students' tweets that I found so valuable for a particular course, invigorated these students to tweet even more fruitful tweets. Other students found Twitter useful because it helped them connect with their current and old friends online. These findings corroborate with earlier findings by Chawinga and Zinn (2016) in which they found that students in Malawi usually use social media such as Facebook, Twitter and WhatsApp to instantly connect with peers currently at the university or at home and to search and locate old friends. The fact that best grades came from group blog posts (as evidenced by an analysis of the tweets and blog posts), suggest that working in groups motivates students to work hard and understand the content better. The findings support a philosophy first proposed by Vygotsky (1980) that learners' knowledge uptake is amplified if they work in groups. Unlike during the era of Vygotsky's sentiments where students had to meet physically in groups to accomplish school assignments, in the social media era, these results show quite clearly that collaboration takes place in virtual environments. The results confirm observations made by prior studies such as that of Wheeler (2010) that have indicated that many of the learning processes from traditional learning are now being offloaded onto, or supported by the new technologies.

Table 4 Reasons for use of social media

\begin{tabular}{lr}
\hline Factors & $\%$ \\
\hline Because it contributed to end of semester grade & 60.9 \\
Because students smartphones and also the availability of computers in the library for accessing such & 59.4 \\
Twitter and blogs & 51.6 \\
Because twitting and blogging skills & 45.3 \\
Helped students learn something that they did not understand in class & 35.9 \\
Because Twitter helped students meet new friends & 34.4 \\
To follow other media outlets such as BBC for News that kept them updated on current affairs & 25.0 \\
Because they were both easier to use compared to other communication methods and also cheaper.
\end{tabular}




\section{What discouraged students from actively participating in Twitter and blog class activities?}

Although the majority participated extensively, findings show that some students (a small proportion though) were not active on Twitter and rarely commented on blogs. Results show that students pay for Internet services at MZUNI which they access only via computers available in the University Library and some computer laboratories. Even if they have smartphones as reported earlier in this paper, they have to buy internet data (commonly called Internet bundles) to surf the Internet. Findings show further that students cannot access University Internet via their mobile devices-Wi-Fi is not accessible by students. This is the reason results presented in Table 5 show that 39 (60.9\%) students mentioned lack of money to buy data bundles which are purchased from Mobiles Network Service providers. Inaccessible Wi-Fi also contributed to 38 (59.4\%) students to indicate that they were not able to access the University Internet. It is encouraging however, that most students have positive attitudes towards using both, blogs and Twitter because according to the findings, only 3 (4.7\%) said they do not like social media implying that the majority of students are ready to use these technologies as long as lecturers are willing to incorporate them into educational activities. The findings echo views by Barczyk and Duncan (2011:275) who claim that "many students already understand its [social media] power and breadth and would likely embrace social networking technology as a learning tool". But how willing are lecturers to adopt these technologies for education purposes considering the fact that prior studies by a trio of researchers (Jacquemin et al., 2014) have shown similar results like mine that students have accepted these technologies more readily than their lecturers attributing the disparity to generational age gap? This is perhaps the reason Veletsianos (2012) suggests that there is need to test the age gap and incorporation of these technologies in a classroom before embarking on a full scale implementation into academic class structures.

As indicated earlier on, the author did not provide any initial training to students on the use of blogs and Twitter although he tweeted some links on how to create blogs. Since respondents had done Information and Communication Technology (ICT) related courses such as End User Computing (ICT1101) and Computer and Communication Technology (ICT1102) when they were in year one helped the students to easily use these social media tools without challenges. Wheeler (2010:114) reports in

Table 5 Reasons for non-use of social media $(n=64)$

\begin{tabular}{llc}
\hline Challenges & $n$ & Percent \\
\hline Lack of money to buy Internet data bundles & 39 & 60.9 \\
Failure to access university Internet for free & 38 & 59.4 \\
Poor university Internet bandwidth & 33 & 51.6 \\
Shortage of computers & 29 & 45.3 \\
Lack of initial training on using Twitter and blogs & 23 & 35.9 \\
Twitter and blog servers were sometimes unavailable & 22 & 34.4 \\
Lack of time to create content for posting on Twitter and blog & 16 & 25.0 \\
Frequent electricity outages & 11 & 17.2 \\
Addicted to Twitter and this affected my other class assignments & 6 & 9.4 \\
Personal: I don't like web 2.0 technologies & 3 & 4.7 \\
\hline
\end{tabular}


his study that students resented using social media (wiki and blogs) because they found it difficult to create their own content. To the contrary, in this study, students did not find this a challenge. The reason is obvious. In Wheeler's study, students required to do other activities off wikis and blogs while in this study, all continuous assessment grades came from students' participation in social media activities. Although the use of social media such as Facebook leads to the "derailment" (Young, 2010) or "can be a counterproductive distraction" (Szapkiw \& Szapkiw, 2011:362) of lecture topics, no such significant upheavals are noted in this study. However, addiction was slowly becoming an obstruction because results presented in Table 5 show that a small portion of students with a score of six $(9.4 \%)$ said they eventually became too addicted to Twitter at times. The majority of students remained focused and determined without being distracted by the social media hype because they were well aware that they could get grades for their participation in social media.

However, in the middle of the semester, the author noticed that some students, particularly those in level two started using these social media especially Twitter irresponsibly by posting emotional tweets. I easily arrested this misconduct by cautioning students through a Twitter post that read: "\#DL \& \#IR: you risk \#losing marks for any unpalatable or derogatory tweets." This was easily contained because as mentioned earlier on, students used their real names as their Twitter user names and they knew that the author could easily trace anyone abusing this social media.

\section{Limitations of the study}

The author monitored the activities of students on Twitter and blogs and this may have to some extent skewed the results. Based on their participation in Twitter and blog activities, the author gave students a grade that contributed towards an overall end of semester grade. This may have as well affected students' natural use of Twitter and blogs. More so, the study did not solicit the views of university management whom by virtue of being policy makers are critical to the adoption of any technology. After all, Tess (2013) is of the opinion that one of the factors that stymies the adoption of social media in higher education is that the responsibility to use these technologies is left to a lecturer with little or no interest from a university level. This stimulates the researcher to suggest that future studies should investigate university policies that are deliberately put in place to foster the take up and use of social media in formal learning contexts.

\section{Personal reflection on the findings}

The researcher was part of the study in the sense that as stated in the methodology, he was the lecturer for both classes. To this end, based on his practical experience throughout this project, the following are his personal experiences worth sharing:

- Using these social media technologies helped the researcher to achieve a rather more quality teaching: students' limitless presence on blogs and Twitter implied that teaching and learning continued even outside the classroom. Questions and comments were posted on these tools even during holidays, weekends and odd hours. In this way, the researcher offered instant assistance to students.

- Unlike other classes that the researcher had previously taught without the use of these technologies, students in these particular classes were more enthusiastic to 
learn. In fact, students rarely missed classes because the content to be discussed was posted well in advance and students were always looking forward to take part in a live discussion in class having conducted a thorough research on a topic under discussion. These experiences are consistent with that of Jones (2015:97) who in his literature class (where Twitter was used) remarked that "We would sometimes go three or four classes without a single student missing class".

- Like any other technologies, using social media in a classroom required the researcher to consider a number of factors such as good Internet which should be accessed for free (unfortunately, this was not the case in this project) and good ICT skills which the researcher and his students had.

- Generally, regardless of the challenges that were faced in using these technologies, benefits accrued were more pronounced because students scored highly in their end of semester examinations; only one student failed a course.

- As one of the first lecturers on Mzuzu University campus to successfully pilot course delivery via social media amid visible challenges, the researcher considers his action to be pioneering though risk taking in the beginning.

\section{Conclusion and recommendations}

Although not essentially generalisable (see the limitations above), the author envisages that the findings will not only add value to the existing literature, but rather, the innovative nature of the research implies that it provides some important insights on which other lecturers intending to use similar technologies in classroom environments can adopt. That is, the study has filled some knowledge gaps in the practical use of social media tools in a university classroom environment. The study has unveiled that students are not only ready and enthusiastic in using social media in the accomplishments of their educational activities. Rather, students are able to practically use these social media practically. The fact that there was an overwhelming response from students in practically using these technologies is a strong proof that students are moving with technology and it just requires instructors to bring these technologies to the classroom. More importantly, much as traditional teaching approaches which are mainly perceived as one-way delivery methods remain common and wide spread in higher education, their effectiveness are enhanced by blending them with social media.

To get the best from social media use in a classroom environment, using them haphazardly should be avoided. Instead, social media works well by clearly defining the purpose for their use or inclusion in a course. Instructors stand to reap more benefits if they effectively incorporate technologies such as social media that leads to long-life learning (achieved through independent learning) amongst students.

Based on the findings of the study, the author suggests some recommendations which if implemented may encourage the use of social media at MZUNI or universities with similar economical and technological backgrounds. Firstly, MZUNI and other institutions of higher learning should make Internet freely accessible or highly subsidised to all students. So too, Wi-Fi should be installed covering the whole campus and should be accessible via students' mobile devices and laptops. Secondly, it should not be taken for granted that students can find means to access Internet when an instructor incorporates Internet based technologies such as social media into a course. Rather, lecturers at MZUNI intending to incorporate social media or related technologies into their 
courses, should make prior arrangements with the MZUNI Library and MZUNI ICT Directorate so that students should access computers without trouble. This becomes paramount if blogs and wikis are to be used because most basic phones rarely support these applications. Third and lastly, using social media haphazardly (see Comm, 2009) comes with no reward. Rather, lecturers intending to use these technologies for pedagogical purposes should set guideline well in advance so that students should be well aware about what the lecturer expects from them.

\section{Areas for further study}

This study targeted Library and Information Science students who have some formally acquired knowledge in ICTs and Internet use. Future researchers may consider conducting a comparative study that experiments the use of such technologies with LIS students and students from the faculties that do not offer ICT related courses.

\section{Author's information}

WINNER DOMINIC CHAWINGA is a lecturer in the Department of Library and Information Science at Mzuzu University, Malawi, with 5 years' teaching experience at university level. He holds a master's degree in Library and Information Studies from the University of the Western Cape (UWC), Bellville, South Africa. This 2 year master's degree was completed in English. He obtained a bachelor's degree in Library and Information Science from Mzuzu UniversityMalawi. This 4 year bachelor's degree was also completed in English. His research interests include institutional repositories, electronic resources, ICTs and development, ICTs in higher education, Web 2.0, e-learning and ICT trends and applications in library and information science. He is the winner of the 2015 best Library and Information Science International Federation of Library Associations and Institutions (IFLA) student paper.

\section{Competing interests}

The author declares that he has no financial or personal relationships which may have inappropriately influenced him in writing this article.

Received: 20 June 2016 Accepted: 7 November 2016

Published online: 25 January 2017

\section{References}

Ajjan, H., \& Hartshorne, R. (2008). Investigating faculty decisions to adopt Web 2.0 technologies: Theory and empirical tests. The Internet and Higher Education, 11(2), 71-80.

Azab, A. N., Abdelsalam, M., \& Gamal, S. (2013). Use of Web 2.0 collaboration technologies in Egyptian public universities: An exploratory study. http://goo.gl/z6w70j. Accessed 20 Aug 2013.

Barczyk, C. C., \& Duncan, D. G. (2011). Social networking media as a tool for teaching business administration courses. International Journal of Humanities and Social Science, 1(17), 267-276.

Bosch, T. E. (2009). Using online social networking for teaching and learning: Facebook use at the university of Cape Town. Communication: South African Journal of Communication Theory and Research, 35(2), 185-200.

Braun, V., \& Clarke, V. (2006). Using Thematic Analysis in Psychology. Qualitative Research in Psychology, 3(2), 77-101.

Browning, L., Gerlich, R. N., \& Westermann, L. (2011). The new HD classroom: a hyper diverse approach to engaging with students. Journal of Instructional Pedagogies, 3(1), 1-15.

Bull, G., Thompson, A., Searson, M., Garofalo, J., Park, J., Young, C., \& Lee, J. (2008). Connecting informal and formal learning experiences in the age of participatory media. Contemporary Issues in Technology and Teacher Education, $8(2), 100-107$.

Chawinga, W. D., \& Zinn, S. (2015). Lecturers' use of Web 2.0 in the Faculty of Information Science and Communications at Mzuzu University, Malawi. Mousaion: South African Journal of Information Studies, 33(4), 62-85.

Chawinga, W. D., \& Zinn, S. (2016). Use of Web 2.0 by students in the Faculty of Information Science and Communications at Mzuzu University, Malawi. South African Journal of Information Management, 18(1). http://dx.doi.org/10.4102/sajim.v18i1.694. Accessed 20 March 2016.

Comm, J. (2009). Fourteen types of tweets. http://joelcomm.com/fourteen-types-of-tweets.html. Accessed 30 Jul 2015.

Conole, G. (2010). Review of Pedagogical Models and their use in e-learning. Milton Keynes: Open University.

Conole, G., \& Alevizou, P. (2010). A literature review of the use of Web 2.0 tools in Higher Education. In A report commissioned by the Higher Education Academy. Milton Keynes: The Open University.

De Wever, B., Hämäläinen, R., Voet, M., \& Gielen, M. (2015). A wiki task for first-year university students: The effect of scripting students' collaboration. The Internet and Higher Education, 25, 37-44.

Deng, L., \& Yuen, A. H. (2011). Towards a framework for educational affordances of blogs. Computers \& education, 56(2), 441-451.

Dzvapatsva, G. P., Mitrovic, Z., \& Dietrich, A. D. (2014). Use of social media platforms for improving academic performance at Further Education and Training Colleges. South African Journal of Information Management, 16(1).

Ellison, N. B. (2008). Social network sites: definition, history, and scholarship. Journal of Computer-Mediated Communication, 13(1), 210-230.

Farkas, M. (2012). Participatory technologies, pedagogy 2.0 and information literacy. Librany Hi Tech, 30(1), 82-94. 
Franklin, T., \& Harmelen, M. (2007). Web 2.0 for content for learning and teaching in higher education. http://www.jisc.ac.uk/ media/documents/programmes/digitalrepositories/web2-content-learning-and-teaching.pdf. Accessed 24 Jan 2015.

Galagan, P. (2010). Burp, chatter, tweet: New sounds in the classroom. T+D, 64(7), 26-29.

Gikas, J., \& Grant, M. M. (2013). Mobile computing devices in higher education: Student perspectives on learning with cellphones, smartphones and social media. The Internet and Higher Education, 19, 18-26.

Harris, A. L., \& Rea, A. (2009). Web 2.0 and virtual world technologies: a growing impact on IS education. Journal of Information Systems Education, 20(2), 137-144.

Jacquemin, S. J., Smelser, L. K., \& Bernot, M. J. (2014). Twitter in the higher education classroom: a student and faculty assessment of use and perception. Journal of College Science Teaching, 43(6), 2-9.

Jones, A. (2015). How Twitter saved my literature class: a case study with discussion. In C. Wankel, M. Marovich, K. Miller, \& J. Stanaityte (Eds.), Teaching Arts and Science with the New Social Media (pp. 91-105). Bingley: Emerald Group Publishing.

Kaplan, A., \& Haenlein, M. (2010). Users of the world, unite! The challenges and opportunities of social media. Business Horizons, 53(1), 59-68.

Kietzmann, J. H., Hermkens, K., McCarthy, I. P., \& Silvestre, B. S. (2011). Social media? Get serious! Understanding the functional building blocks of social media. Business Horizons, 54(3), 241-251.

Kim, I., \& Kuljis, J. (2010). Applying content analysis to Web based content. In: Proceedings of Information Technology Interfaces (ITI), 2010 32nd International Conference (pp. 283-288), June 21-24, 2010: Cavtat, Croatia.

Kwanya, T., Stilwell, C, \& Underwood, P. (2012). The application of Web 2.0 tools by libraries in Kenya: A reality check. http://scecsal.viel.co.ke/images/e/ea/TheApplicationOfWeb2.0ToolsByLibrariesIn_Kenya-ARealityCheck.pdf. Accessed 24 Oct 2014.

Maloney, E. (2007). What Web 2.0 can teach us about learning. The Chronicle of Higher Education, 25(18), B26.

Mason, R. (2006). Learning technologies for adult continuing education. Studies in Continuing Education, 28(2), 121-133.

Mazman, S. G., \& Usluel, Y. K. (2010). Modeling educational usage of Facebook. Computers \& Education, 55(2), 444-453.

Menkhoff, T., Chay, Y. W., Bengtsson, M L., Woodard, C. J., \& Gan, B. (2014). Incorporating microblogging ("tweeting") in higher education: lessons learnt in a Knowledge Management Course. Computers in Human Behavior. http://www. sciencedirect.com/science/article/pii/S074756321400681. Accessed 4 Dec 2015.

O'Reilly, T. (2005). What is Web 2.0: design patterns and business models for the next generation of software? Sebastopol: O'Reilly Media. https://mpra.ub.uni-muenchen.de/4578/1/MPRA_paper_4578.pdf. Accessed 10 Aug 2015.

Parr, B. (2009). How to get the most out of Twitter \#hashtags. http://mashable.com/2009/05/17/twitter-hashtags/. Accessed 8 Jun 2015.

Roblyer, M. D., McDaniel, M., Webb, M., Herman, J., \& Witty, J. V. (2010). Findings on Facebook in higher education: a comparison of college faculty and student uses and perceptions of social networking sites. The Internet and Higher Education, 13(3), 134-140.

Schroeder, J., \& Greenbowe, T. J. (2009). The chemistry of Facebook: using social networking to create an online community for the organic chemistry laboratory. Innovate: Journal of Online Education, 5(4), 1-7.

Soares, D. A. (2008). Understanding class blogs as a tool for language development. Language Teaching Research, 12(4), 517-533.

Szapkiw, A., \& Szapkiw, M. (2011). Engaging higher education students through tweeting. In S. Barton, J. Hedberg, \& K. Suzuki (Eds.), Proceedings of Global Learn Asia Pacific (pp. 360-364). Melbourne: Global Learn Asia Pacific.

Terrell, J., Richardson, J., \& Hamilton, M. (2011). Using Web 2.0 to teach Web 2.0: a case study in aligning teaching, learning and assessment with professional practice. Australasian Journal of Educational Technology, 27(Special issue), $846-862$.

Tess, P. A. (2013). The role of social media in higher education classes (real and virtual)-A literature review. Computers in Human Behaviour, 29(5), A60-A68.

Veletsianos, G. (2012). Higher education scholars' participation and practices on Twitter. Journal of Computer Assisted Learning, 28(4), 336-349.

Vygotsky, L. S. (1980). Mind in society: the development of higher psychological processes. Cambridge: Harvard University Press.

Waycott, J., Gray, K., Clerehan, R., Hamilton, M., Richardson, J., Sheard, J., \& Thompson, C. (2010). Implications for academic integrity of using web 2.0 for teaching, learning and assessment in higher education. International Journal for Educational Integrity, 6(2), 8-18.

Wheeler, S. (2010). Open content, open learning 2.0: using wikis and blogs in higher education. In Changing cultures in higher education (pp. 103-114). Heidelberg: Springer Berlin.

Young, J. R. (2010). Teaching with Twitter: not for the faint of heart. Education Digest: Essential Readings Condensed for Quick Review, 75(7), 9-12.

\section{Submit your manuscript to a SpringerOpen ${ }^{\circ}$ journal and benefit from:}

- Convenient online submission

- Rigorous peer review

- Immediate publication on acceptance

- Open access: articles freely available online

- High visibility within the field

- Retaining the copyright to your article

Submit your next manuscript at $>$ springeropen.com 